\title{
Constructing A Business Process Network System "A-BPNS-NPD"
}

Takayuki Iida, Aoyama Gakuin University, Japan Ryosuke Mihara, Aoyama Gakuin University, Japan Kakuro Amasaka, Aoyama Gakuin University, Japan

\begin{abstract}
The authors came up with Amasaka laboratory's Business Process Network System for New Product Developments - A-BPNS-NPD - a business process network system that supports improvements in the way businesses approach new product development. Specifically, it is a core system with four components, each of which is designed to clarify the unspoken business processes that companies use in new product development. The first component is a support system for visualizing business processes. The second is a support system for better planning. The third is a support system for work progress management, which includes a support system for passing on know-how and for expansion and growth. The fourth component is a new product development business process approach model to help companies systematically put the other components into action. The A-BPNS-NPD developed by the authors was verified at manufacturing companies and the desired results were obtained.
\end{abstract}

Keywords: Business Process; New Product Developments; A-BPNS-NPD

\section{INTRODUCTION}

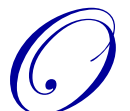

ffering products with higher added value, shortening development lead times, and reducing costs have been increasingly critical tasks for corporations in recent years. The number of product recalls has also been increasing year by year-another factor that points to the need for reform in the business processes used to develop new products. One concern for business managers and staff is improving tacit business processes and setting up a business process system that allows personnel to share the value of their work with others. In order to address these challenges, the authors came up with Amasaka laboratory's Business Process Network System for New Product Developments - A-BPNS-NPD - a business process network system that supports improvements in the way businesses approach new product development.

Specifically, it is a core system with four components, each of which is designed to clarify the unspoken business processes (people, things, information, costs, etc.) that companies use in new product development. The first component is a support system for visualizing business processes. The second is a support system for better planning. The third is a support system for work progress management, which includes a support system for passing on know-how and for expansion and growth. The fourth component is a new product development business process approach model to help companies systematically put the other components into action. The A-BPNS-NPD developed by the authors was verified at manufacturing companies and the desired results were obtained.

\section{BACKGROUND}

\section{The Present State Of New Product Developments}

Today, there are a multitude of functional departments (product planning, research and development, design, prototype testing, purchasing and procurement, production preparation, production engineering, manufacturing, inspection, logistics, and sales) involved in the business processes used to develop new products, and the procedure must go through product planning, research (searching for future needs), development design, purchasing, production engineering, and finally market monitoring. 
One of the problems with this process is that division of labor within the company causes the know-how associated with each task to become tacit or unspoken. Departments are aware of their own problems, but they often become harder to recognize as they spread to other departments as well (Kubota, Okada, Sekiguchi and Imanoya, 2005). To resolve this problem, the different parts of the company must stop working independently and build interdepartmental collaboration. One outstanding problem with division of labor is the extended amount of time it takes to resolve the problems that arise in the new product development process. It is for this reason that the authors thought it necessary to create a framework for new business process reform - reform that would aim to make quality in the business processes used to develop new products more reliable and to ensure that those processes fostered systematic, organized collaboration among functional departments (Hajo and Jan, 2011; Murata, Mibe and Isobe, 2010).

\section{Classification Of New Product Developments}

The work activities of companies today may generally be divided into ranks. Figure 1 shows the classification of new product developments. Rank 1 tasks are simple tasks with no fluctuations in terms of cost and delivery timeframe, Rank 2 tasks are general tasks that have fluctuations in terms of cost and delivery, and Rank 3 tasks are value-creation tasks with even greater differences in costs and delivery timeframes (Amasaka, 2005). The authors have already conducted research on Rank 1 and Rank 2 tasks (Sakai, Waji, Nakamura and Amasaka, 2011; Nakamura, Yamaji and Amasaka, 2011), so this study will address Rank 3 tasks (Mihara, Nakamura, Yamaji and Amasaka, 2010).

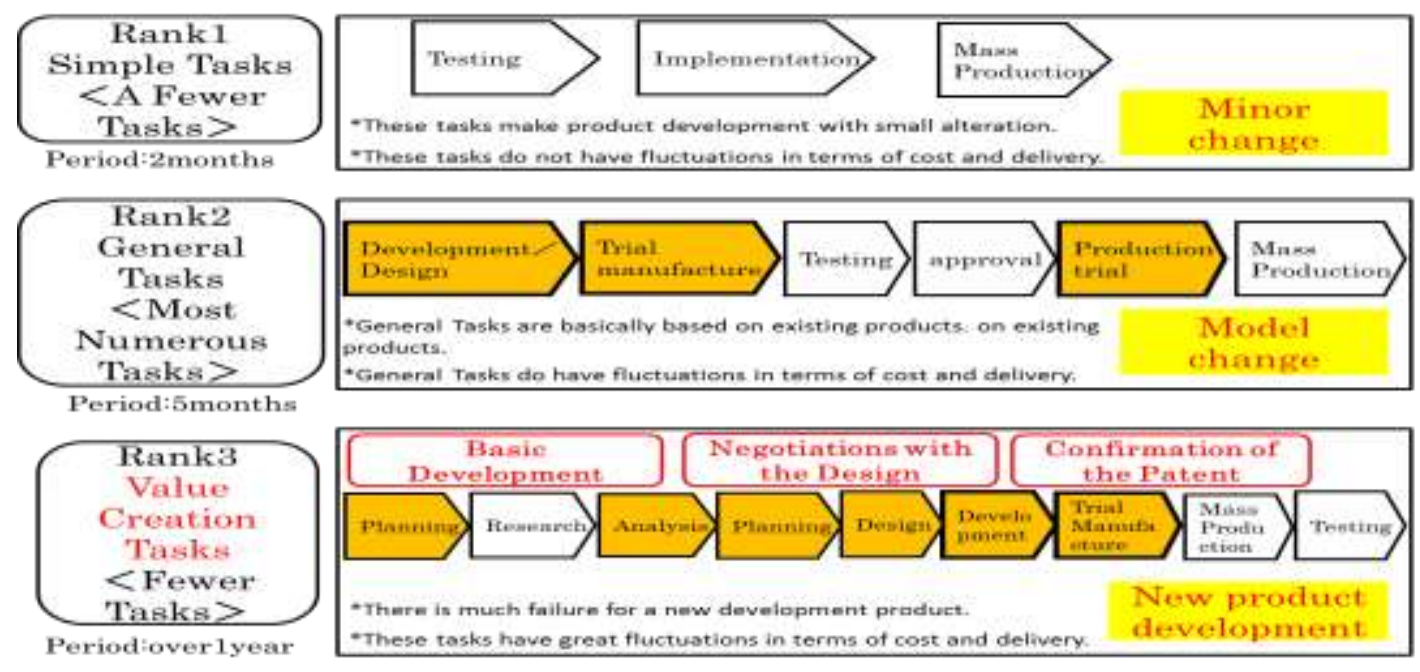

Figure 1: Classification Of New Product Developments

\section{Pinpointing Problems Of Value Creation Tasks}

In order to pinpoint the problems companies are currently experiencing when it comes to value-building tasks (for example, business processes and detailing/communicating information), the authors first held interviews with people involved in product development tasks at companies that manufacture consumer products. A freeresponse questionnaire was conducted at five manufacturers, and the results were used to set up an exhaustive list of problem areas. Examples of the problems identified were "an inability to manage tasks due to fragmentation", "business processes rely on individuals", "we're not getting the information we need to carry out tasks", and "we are collecting information, but it's not getting put to use".

Because of these problems, many respondents reported facing a dilemma whereby the progression speed and quality of tasks were becoming increasingly inconsistent. The results of the interviews and surveys were summarized to yield five major problems currently facing product development tasks: 1) A lack of information about product users, 2) inconsistent quality in product planning, 3) a lack of information on product design, 4) 
problems with business processes, and 5) difficulty making use of information systems. In order to comprehensively address these problems, the authors came up with the measures described in the next section.

\section{PLANNING A BUSINESS PROCESS NETWORK SYSTEM “A-BPNS-NPD”}

\section{Construction of "A-BPNS-NPD"}

Figure 2 shows the construction of A-BPNS-NPD.

1. The support system for planning (A-BPNS-NPD Plan) consists of a company-defined standard work process based on past experiences when a given project begins, making it possible to carefully investigate current work processes. These functions will help newcomers grasp the tasks in a shorter period of time and improve the quality of the planning progress by making use of past examples.

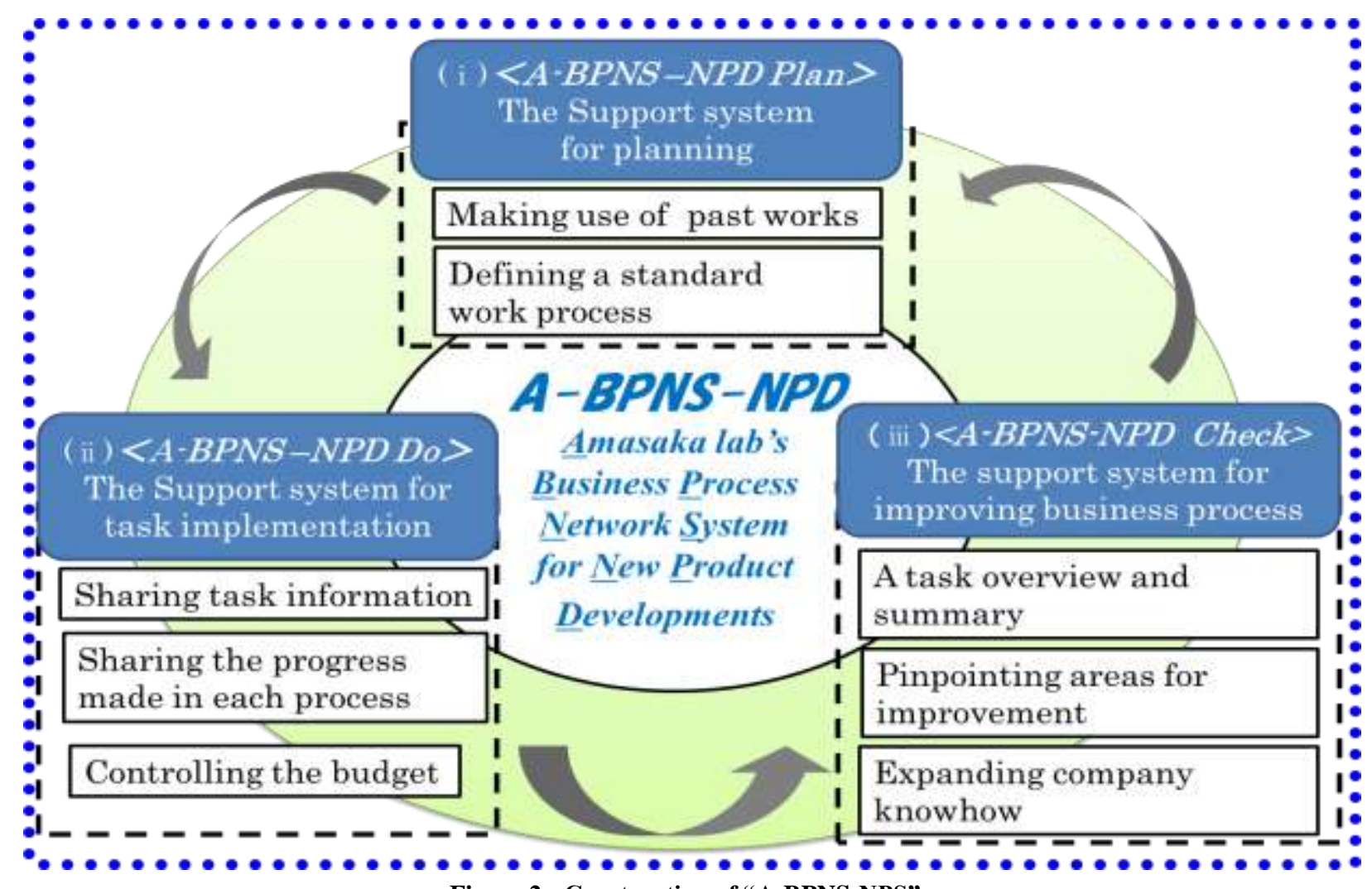

Figure 2: Construction of "A-BPNS-NPS"

2. The support system for task implementation - A-BPNS-NPD Do - makes it possible for companies to evaluate their projects from a process standpoint. This is done by sharing task information throughout the company - information like the groups in charge of each product, the personnel leading each task, individual product specifications, and the progress being made in each process. In terms of controlling the budget as well, this system also provides a framework for displaying and managing the budget so that companies have a clear schedule of fund usage as well as budget forecasts to work with.

3. The support system for improving business processes - A-BPNS-NPD Check - involves preparing a work completion report to serve as a task overview and summary. By comparing this report with the standard business process diagram created during the planning process, companies can pinpoint areas for improvement; for example, by identifying wasteful or time-consuming tasks or finding areas where budgetary cutbacks might be made using the chronologically recorded budget control schedule. Coming up with improvement measures based on the causes for failure identified in these resources will also help pass 
along and expand company know-how. By making use of the three systems outlined above and faithfully repeating the A-BPNS-NPD cycle, companies can thus resolve the problems and issues facing their valuebuilding tasks.

\section{Conception of A-BPNS-NPD Networking System Model}

Figure 3 shows the conception of A-BPNS-NPD Networking System Model. This is a detailed general configuration of the system used to support the implementation of A-BPNS-NPD. The exchange of information is displayed for each department so that knowledge can be shared throughout the company.

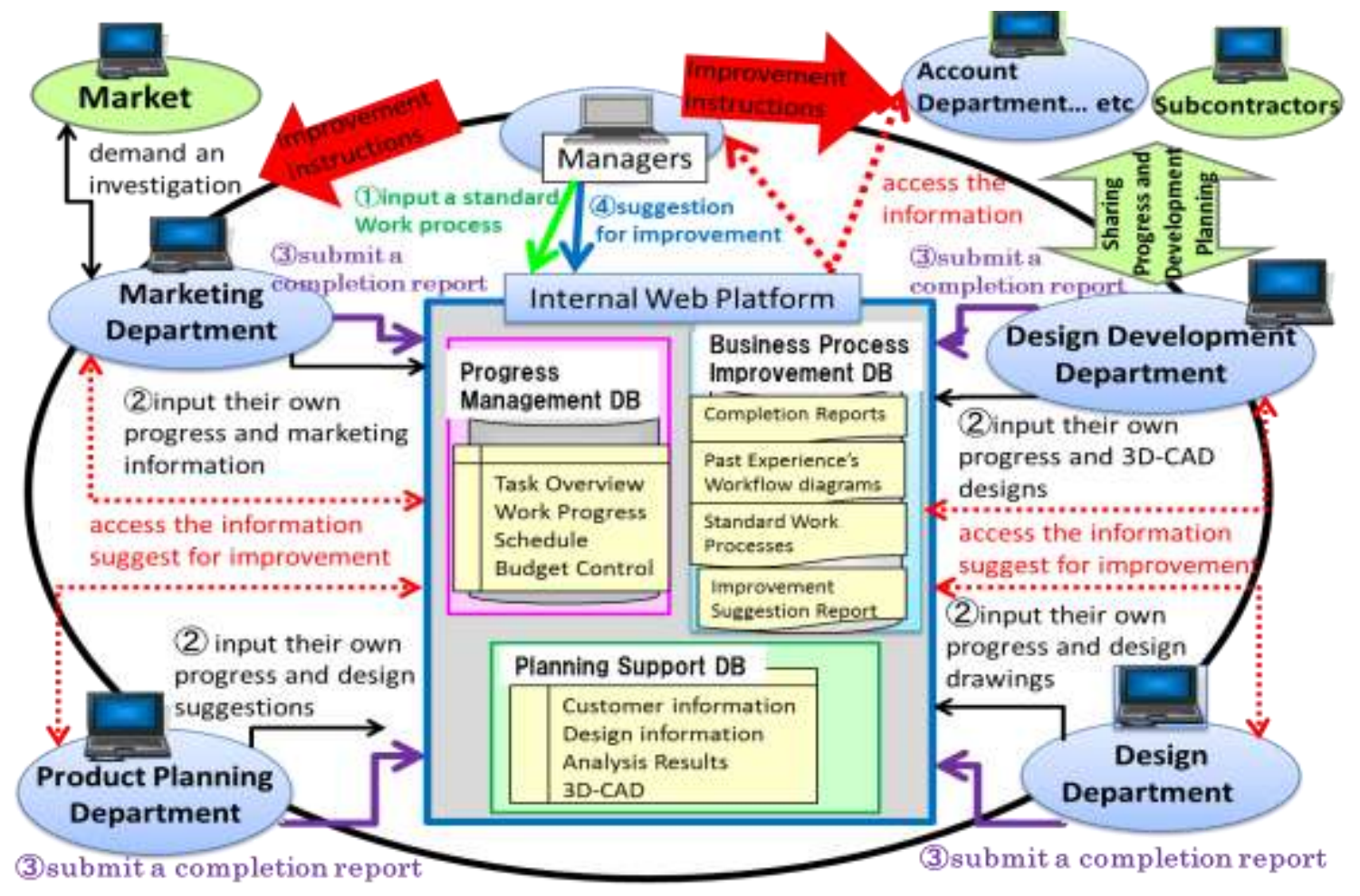

Figure 3: Conception of A-BPNS-NPD Networking System Model

The system supports A-BPNS-NPD in the following way. First, managers input work processes for the project into the system. Then, depending on how far along the project is, the marketing, product planning, design, and design development departments each enter their own progress and marketing information as needed, in addition to inputting design suggestions, design drawings, and 3D-CAD designs. When the project is complete, each department then submits a completion report. The information created during the course of these work tasks is managed separately in a progress management database, Business Process improvement database, and planning support database.

Managing the information via a dedicated internal web platform allows individual departments to access the information and offer suggestions for improvement at any time. Managers can also access the information and instruct the individual departments on ways to improve. The authors created the A-BPNS networking system as a network environment that allows companies to implement the above actions, thus maximizing the effectiveness of utilizing A-BPNS-NPD and helping to improve the quality of value-building tasks (Amasaka and Sakai, 2011). 


\section{APPLICATION EXAMPLES OF "A-BPNS-NPD”}

This study dealt with value-building Rank 3 product development tasks. A-BPNS-NPD was constructed through prior research done at the Amasaka Laboratory and application examples from joint research with Yamaha Motor Co., Ltd (Kuniyoshi, 2005).

\section{A-BPNS Application Approach Model}

Figure 4 shows the A-BPNS-NPD Application Approach Model.

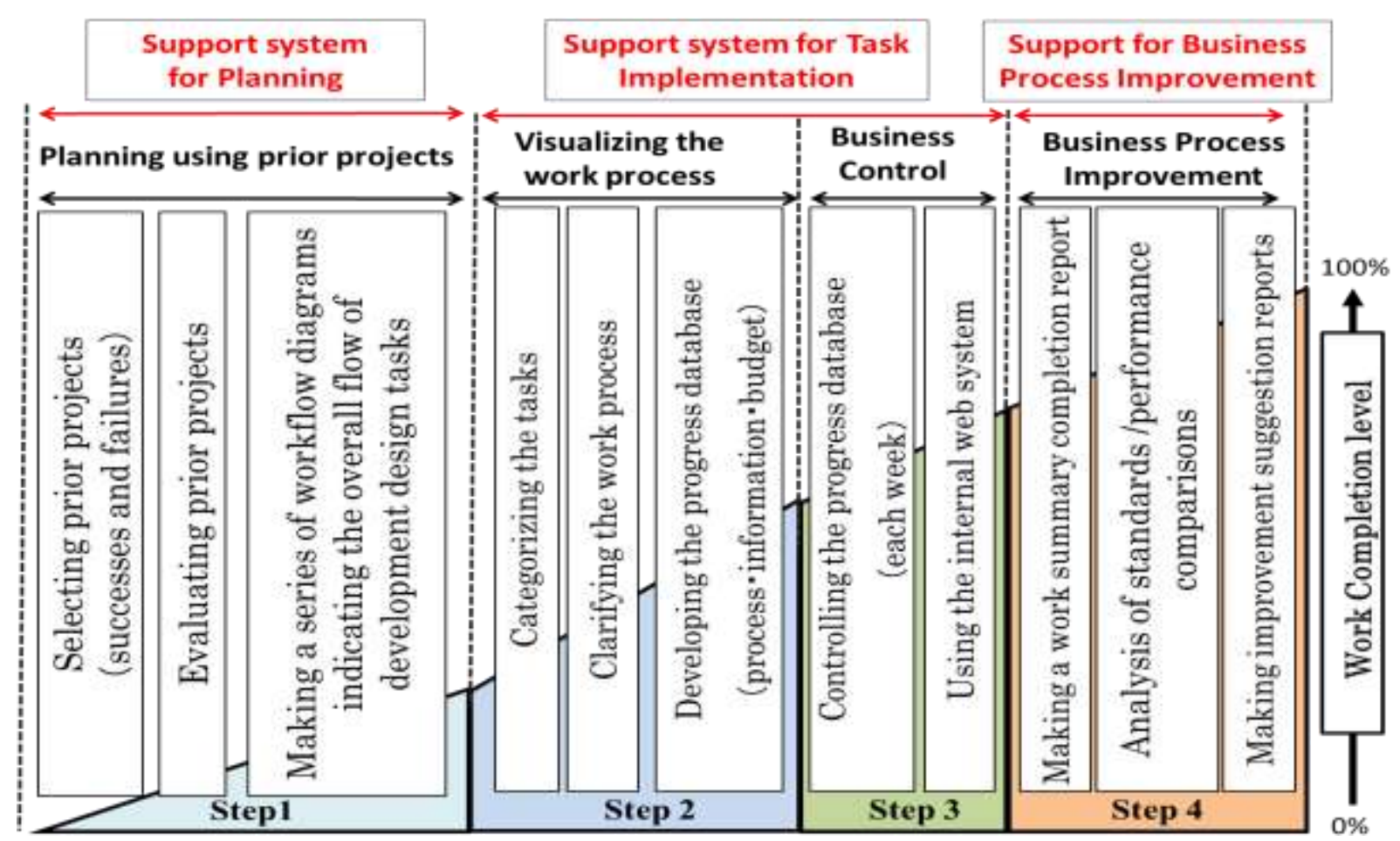

Figure 4: A-BPNS-NPD Application Approach Model

\section{STEP1: Planning Using Prior Projects}

Using prior projects as reference companies, select examples of successes (projects that successfully met their deadlines) and failures (projects that failed to meet their deadlines) and review the work completion reports, summary, work process flowcharts, and progress management information for those projects. These are used for the new project, which is then evaluated. Next, an overall workflow diagram is created. After preparing a series of workflow diagrams indicating the overall flow of development design tasks, the flow of people, things, money, information, and budgets is used to visualize how work is carried out.

\section{STEP2: Visualizing The Work Process}

Using the workflow diagrams prepared in STEP 1, tasks are categorized and a progress database is developed for the groups of work processes and work information. This involves defining standard work times, scheduled implementation dates, and personnel in charge for each task, gradually clarifying the work process and successively revising it so that it can be visualized in a more detailed manner. This will allow companies to share work progress status throughout the company and support better task management. 


\section{STEP3: Business Control Using A System}

Each week, implementation dates and actual times from the work process being carried out are input into the work progress database. Work progress management and information is then shared using the database as well as the internal web system, making it possible for managers to control and evaluate work and enabling development leaders to check the progress of other departments. In addition, budget control and schedule management for personnel in charge and managers is also carried out as needed using the budget control functions of the progress database and designated internal web platform, as well as the schedule management function of the system. This helps companies diagnose budget overages while work is in progress as well as determine work priorities.

\section{STEP4: Business Process Improvement}

When work is complete, a work summary completion report is prepared. The completion report includes project information and problem resolution workflows, as well as key decision-making points and the data that were useful in making those decisions, problem resolutions and a summary of actions taken, a development schedule and any special notes. In addition, progress information properly entered during the course of the project (progress information on work processes, budget control information, and work information, including mandatory product specifications), as well as overall workflow charts, are collected and utilized in planning the next new project.

\section{New Product Developments Business Process Model using A-BPNS-NPD}

The above research was applied to the creation of a design concept used to come up with a new design for a motorized bicycle. The business process model used is shown in Figure 5.

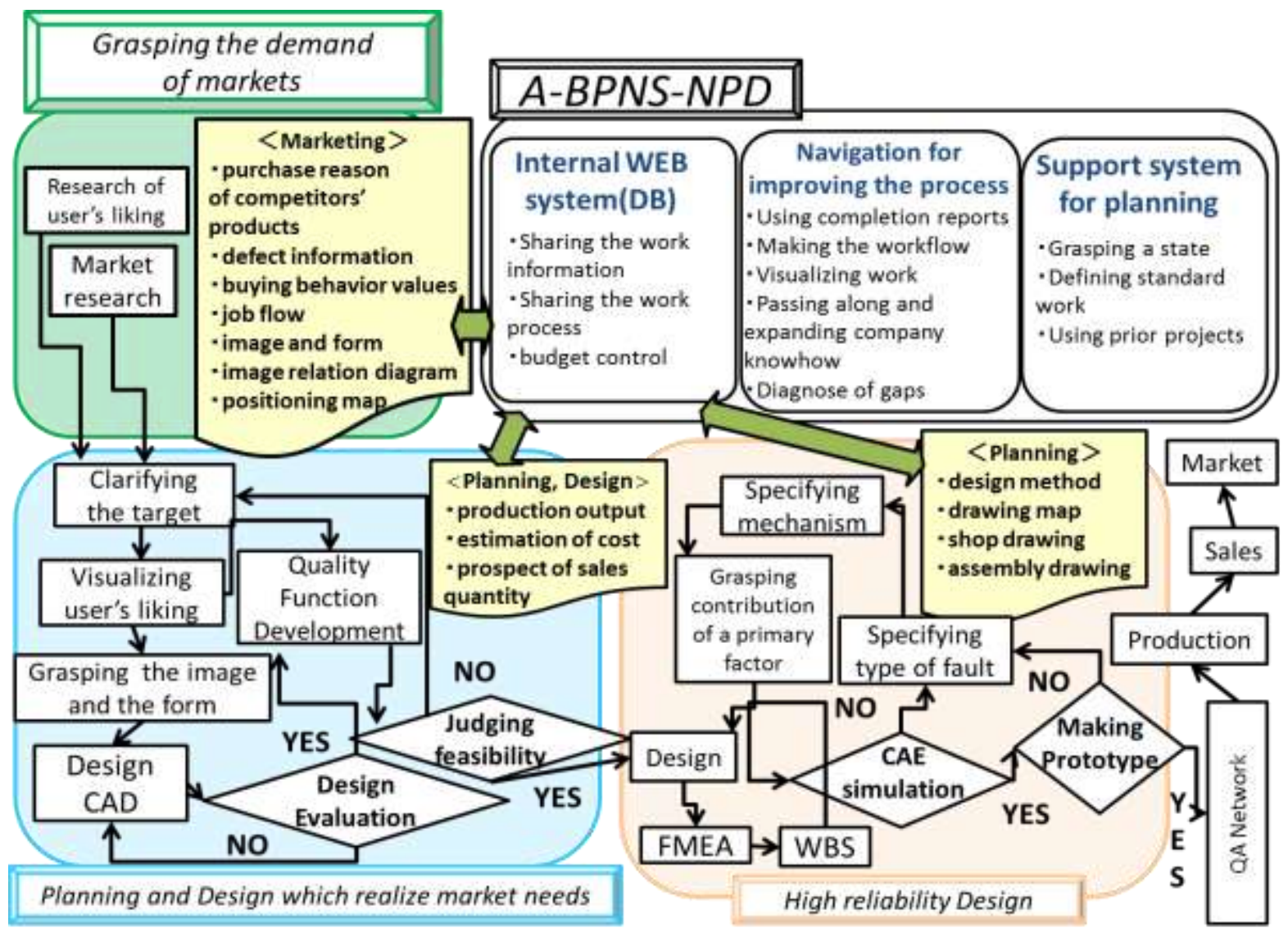

Figure 5: New Product Developments Business Process Model Using A-BPNS-NPD 
The research was applied to specific work processes in each stage according to the following workflow. In the marketing stage, market needs were identified. In the planning and designing stage, those market needs were incorporated into plans and designs. During the engineering stage, highly reliable designs were prepared. The figure shows the data related to each step as it was managed through A-BPNS-NPD (Shoudai, 2008; Yaguchi, Iwata, Ito, Klein and Hukuda, 2009).

\section{Constructing A-BPNS-NPD}

Based on consideration of the work process in the application example above, A-BPNS-NPD was constructed with the following functions and the system utilized the completion reports and improvement suggestion report as shown in Figure 6:

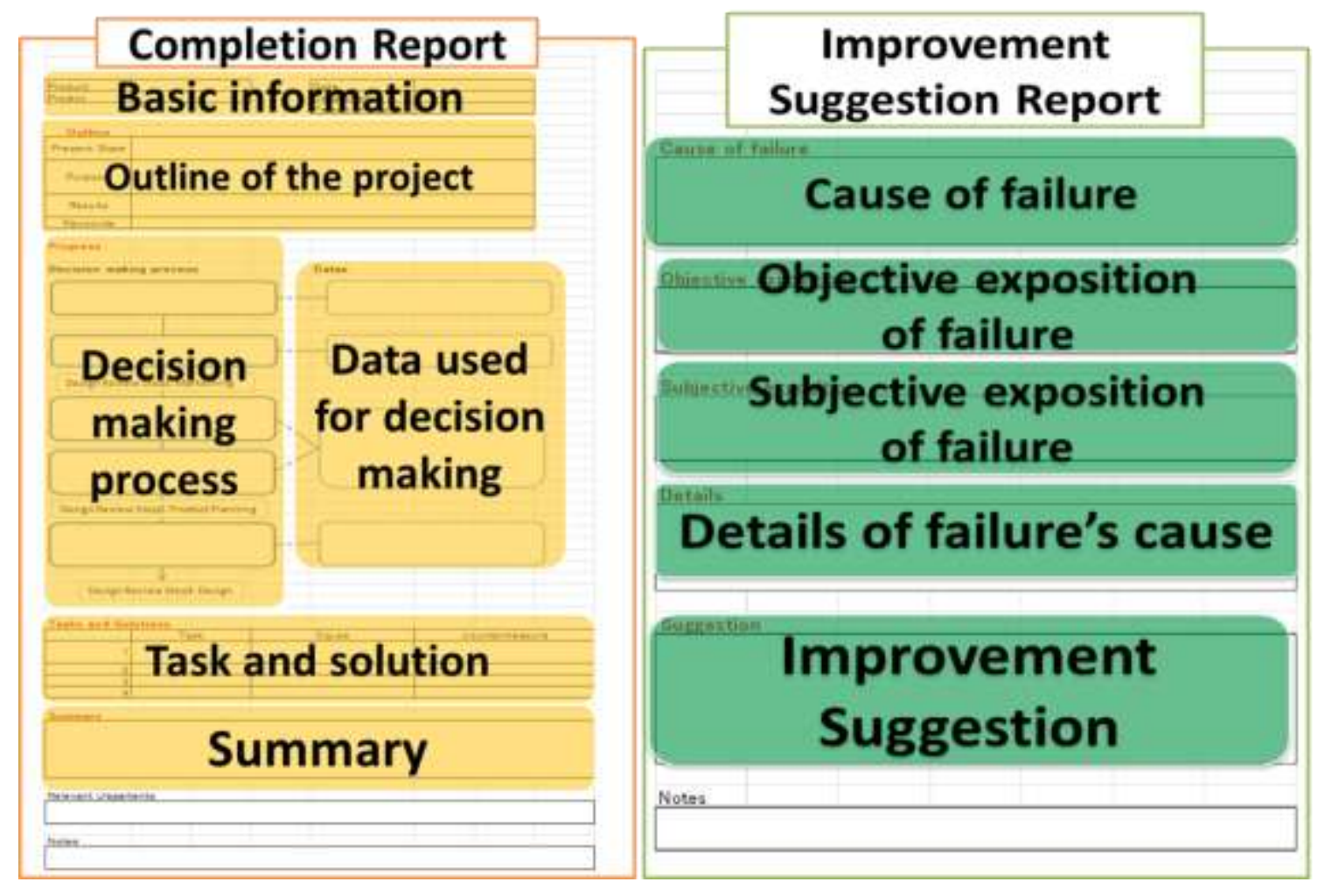

Figure 6: Completion Report and Improvement Suggestion Report

1. In the support system for planning - A-BPNS-NPD Plan - past projects are selected in order to access the completion reports, standards/performance comparisons, and improvement suggestion reports for those projects. These are used to help improve the quality of planning tasks.

2. Figure 7 shows the screen of the international company web. In the support system for task implementation - A-BPNS-NPD Do - information is shared on the work progress of every member in the project using the internal web platform. This makes it possible to compare budget totals and performance totals from each DR step, which in turn supports the implementation of work tasks. 


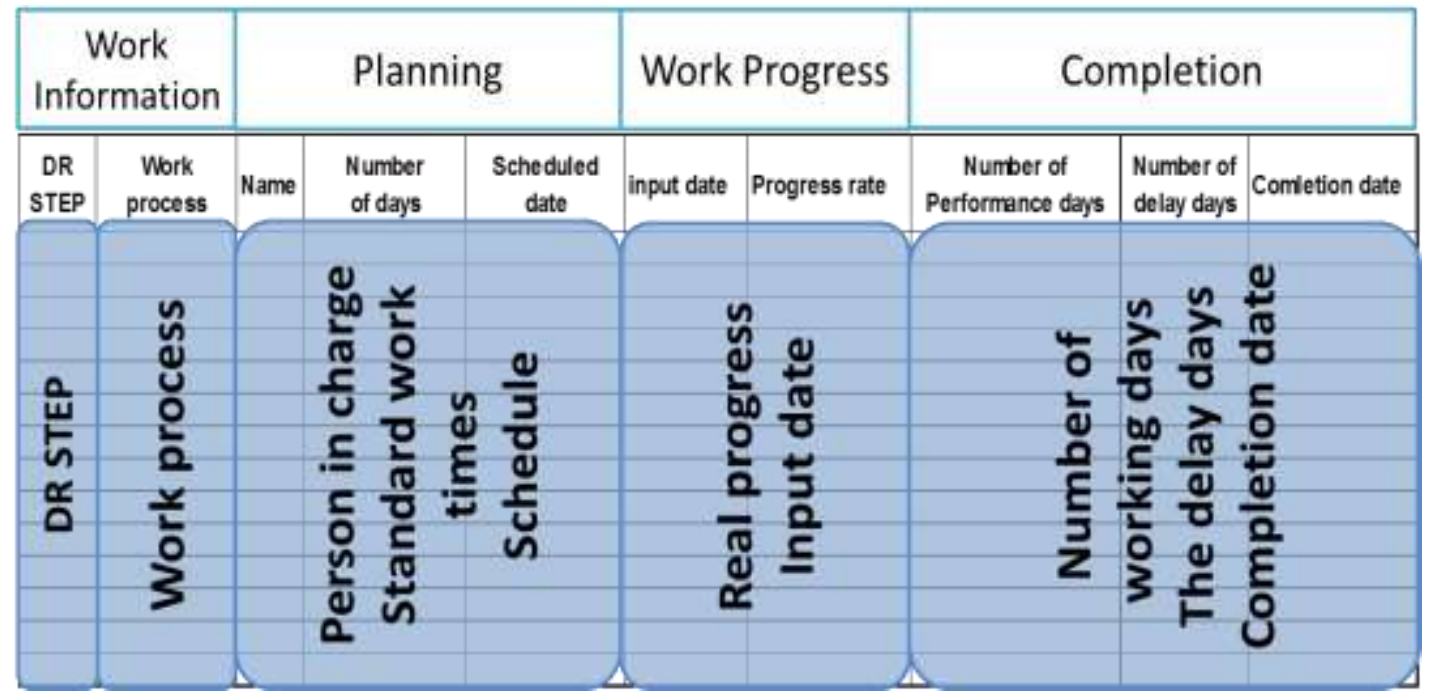

Figure 7: The Screen Of The International Company Web

3. In the support system for improving business processes - A-BPNS-NPD Check - as shown in Figure 8 - a work completion report is prepared. This is used to reflect on the project and come up with suggestions for improvement that will promote better planning quality in the future. In addition, this system has planning and performance comparison items, and flowcharts of standard work and actual work are displayed alongside one another in order to identify time-consuming tasks. A budget/performance graph also allows companies to pinpoint tasks that exceeded their budget.

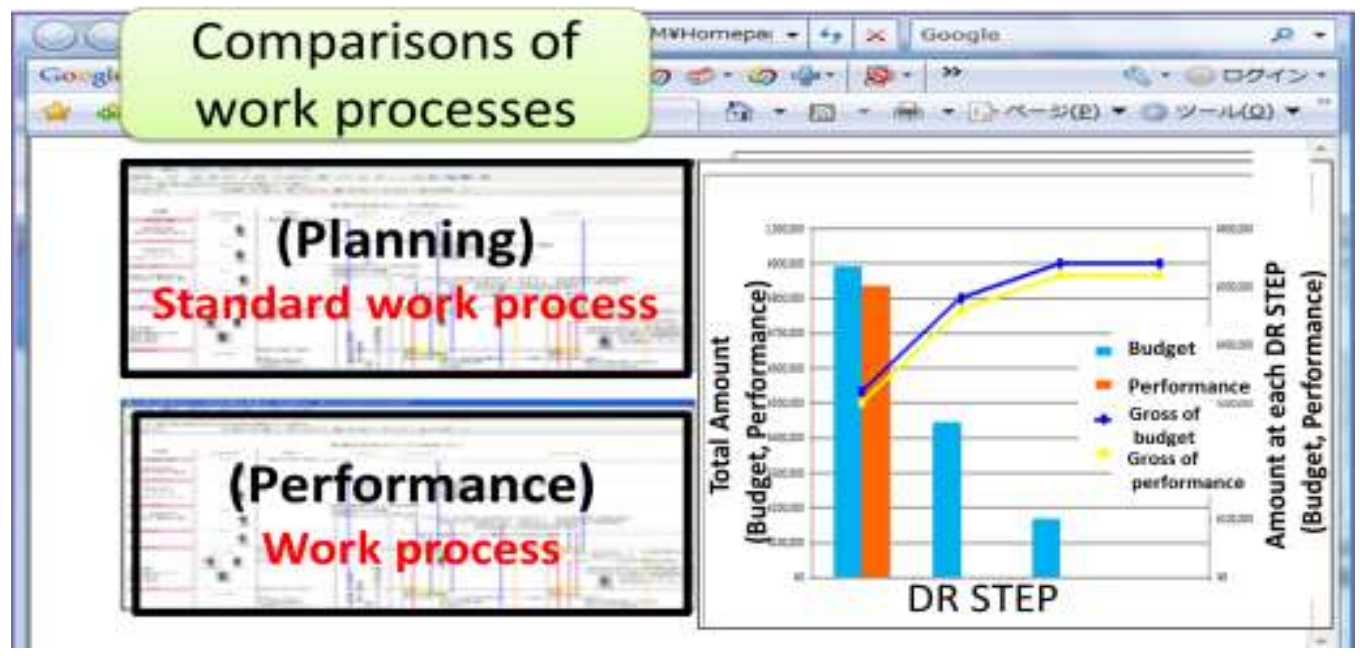

Figure 8: Business Process Improvement Support System <A-BPNS-NPD Check>

\section{Effectiveness of using A-BPNS-NPD}

In order to verify the effectiveness of using A-BPNS-NPD, the authors asked four members of a product planning division and design division of a manufacturer cooperating with this study to evaluate it as well as the ABPNS-NPD application approach. The interviewees responded that the support system for planning (A-BPNS-NPD Plan), support system for work implementation (A-BPNS-NPD Do), and support system for business process improvement (A-BPNS-NPD Check) contributed to the utilization of past experiences, implementation of current tasks, and task improvement, respectively. 
They also noted that the system could be used to resolve current problems in their company related to value-building tasks. Requests for the future included the creation of a business approach model that would include scientific explanations in areas like data analysis.

\section{CONCLUSION}

This study sought to resolve five problem areas associated with corporate product development: 1) a lack of information about product users, 2) inconsistent quality in product planning, 3) a lack of information on product design, 4) problems with business processes, and 5) difficulty making use of information systems. In order to do this, a systematic business approach method to visualize business processes (people, etc.) that companies use in new product development - a Business Process Network System (A-BPNS-NPD) - with diagnostic functions that can execute countermeasures - was developed and verified. A navigation system called A-BPNS-NPD with diagnostic functions that can execute countermeasures was developed and verified. The development of A-BPNS-NPD improved the efficiency of new product development and value-building work while helping to pass along and expand company know-how. The desired results were thus obtained.

\section{AUTHOR INFORMATION}

Takayuki Iida is a graduate student of the Graduate School of Science and Engineering at Aoyama Gakuin University, Japan. E-mail: c5611147@aoyama.jp

Ryosuke Mihara received his Master of Engineering degree from the Graduate School of Science and Engineering at Aoyama Gakuin University, Japan. E-mail: c5607141@aoyama.jp

Dr. Kakuro Amasaka is a Professor in the College of Science and Engineering at Aoyama Gakuin University, Japan. He received his Ph.D. degree in Precision Mechanical and System Engineering, Statistics and Quality Control at Hiroshima University in 1997. Since joining Toyota Motor Corporation in 1968, He worked as a quality control consultant for many divisions, and the General Manager of the TQM Promotion Division (1998-2000). His specialty is New JIT, Science TQM, Science SQC, Numerical Simulation (CAE) and Customer Science. Now, He has been serving as the vice chairman of JSPM (2003-2007) and JOMSA (2008-2010), the director of JSQC (2001-2003) and the commissioner of the Deming Prize judging committee (2002-present). Now, he is inaugurated as the chairman of JOMSA (2011-2012). E-mail: kakuro_amasaka@ise.aoyama.ac.jp (Corresponding author)

\section{REFERENCES}

1. Amasaka, K, (2005), "Constructing a Customer Science Application System “CS-CIANS"- Development of a Global Strategic Vehicle "Lexus" Utilizing New JIT -," WSEAS Transactions on Business and Economics, Issue 3, Vol. 2, pp. 135-142.

2. Amasaka, K. and Sakai, H. (2011), The New Japan Global Production Model "NJ-GPM": Strategic Development of Advanced TPS, The Journal of Japanese Operations Management and Strategy, Vol. 2, No. 1, pp. 1-15.

3. Hajo, R. and Jan, M. (2011), “A Study Into the Factors That Influence the Understandability of Business Process Models", IEEE Transactions on Systems, Man, and Cybernetics-Part A: Systems and Humans, Vol. 41, No. 3, pp. 449-462.

4. Kubota, A., Okada, K., Sekiguchi, K., and Imanoya, F. (2005), “A Case of Business Process Innovation for Product Development in Semiconductor and Integrated Circuit Business", Journal of the Society of Project Management, Vol. 7, No. 3, pp. 38-43.

5. Kuniyoshi, M. (2005), "New Proposal of Business Process - Example of automobile exterior design using text mining method -“, Master's thesis of Aoyama Gakuin University, Amasaka Laboratory (unpublished)

6. Mihara, R., Nakamura, M., Yamaji, M., and Amasaka, K. (2010), "Study on Business Process Navigation System "A-BPNS "”, International Journal of Management \& Information Systems, Vol. 14, No. 2, pp. 5158 . 
7. Murata, D., Mibe, R., and Isobe, Y. (2010), "Proposal of a Business Process Verification Method using Orders of Tasks", Proceedings of The Institute of Electronics, Information and Communication Engineers, Vol. 109, No. 367, pp. 67-72.

8. Nakamura, M., Yamaji, M., and Amasaka, K., (2008), "Construction of Business Process Navigation System "A-BPNS"', Proceedings of The 38th Annual Conference of the Japanese Society for Quality Control, Vol. 1, No. 1, pp. 161-164.

9. Sakai, H., Waji, M., Nakamura, M. and Amasaka, K. (2011), "Establishment of "A-PPNS", A Navigation System for Regenerating the Software Development Business", Industrial Engineering \& Management Systems, Vol. 10, No. 1, March 2011, pp. 44-54.

10. Shoudai, Y. (2008), "New Product Developments in the Design View Point: Examination of design liking using structural equation modeling", Proceedings of The Behaviormetric Society of Japan, Vol. 34, No. 1, pp. 70-71.

11. Yaguchi, T., Iwata, A., Ito, T., Klein, M., and Hukuda, N. (2009), "Proposal The Method of Sharing Business Process Knowledge in Global Off shore Development”, Proceedings of The Information Processing Society of Japan, Vol. 71, No. 1, pp. 219-220. 